\title{
Le discours de la méthode : la conception par les sionistes allemands de la colonisation juive en Palestine (1896-1919)
}

\section{Olivier Baisez}

\section{OpenEdition}

\section{Journals}

Édition électronique

URL : http://journals.openedition.org/ifha/7412

DOI : $10.4000 /$ ifha. 7412

ISSN : 2198-8943

\section{Éditeur}

IFRA - Institut franco-allemand (sciences historiques et sociales)

\section{Édition imprimée}

Date de publication : 1 décembre 2013

ISSN : 2190-0078

\section{Référence électronique}

Olivier Baisez, «Le discours de la méthode : la conception par les sionistes allemands de la colonisation juive en Palestine (1896-1919) », Revue de l'IFHA [En ligne], 5 | 2013, mis en ligne le 17 février 2014, consulté le 03 mai 2019. URL : http://journals.openedition.org/ifha/7412 ; DOI : 10.4000/ ifha.7412

Ce document a été généré automatiquement le 3 mai 2019.

(CIFHA 


\title{
Le discours de la méthode : la conception par les sionistes allemands de la colonisation juive en Palestine (1896-1919)
}

\author{
Olivier Baisez
}

1 Cette étude entend se démarquer des approches traditionnelles du sionisme pour l'étudier en tant que fait de civilisation allemande, dans le cadre des études germaniques et judéo-allemandes. Elle se conçoit comme une contribution triple à l'histoire intellectuelle du sionisme, à celle de la colonisation et à celle de l'Allemagne wilhelmienne. Croiser ainsi les perspectives sur l'objet de l'étude permet d'en reconfigurer la perception. Les conceptions des sionistes allemands sont en effet resituées dans leur contexte intellectuel et examinées en regard de celui-ci. L'attention se porte sur les méthodes préconisées par les sionistes allemands pour organiser et réussir un projet atypique de colonisation. C'est l'« outillage mental» (Lucien Febvre) des acteurs qui est au cœur du propos. La Palestine à coloniser est pour eux la surface de projection de représentations déterminées par l'évolutionnisme, l'historicisme, le positivisme et l'orientalisme façonnant une «société impériale " (Christophe Charle) telle que l'Empire allemand.

2 L'analyse s'appuie principalement sur l'exploitation intensive d'un corpus de publications sionistes à caractère technique, spécialisées dans les problèmes pratiques de la colonisation, couvrant une période qui s'étend de l'organisation du sionisme en mouvement politique à la suite de la publication par Theodor Herzl du manifeste L'État des Juifs en 1896 jusqu'à la fin de la Première Guerre mondiale (en incluant l'année 1919, celle des secousses révolutionnaires et des négociations de paix). Ce corpus est complété par les organes de presse généralistes du mouvement sioniste et par les monographies d'une sélection raisonnée de personnalités dont on retrace le cheminement intellectuel, les options méthodologiques, les positionnements idéologiques et les formes d'engagement. 
Le texte est découpé en onze chapitres thématiques, eux-mêmes ordonnés en trois parties intitulées «Concepts", "Méthodologies» et "Instruments", qui reflètent une progression globale du général au particulier et permettent de mettre en évidence les axes structurants d'un véritable « discours sur la méthode ».

Par leur manière de poser les problèmes, les sionistes allemands se placent dans la continuité de l'« école historique allemande de l'économie ». La relation souvent postulée entre sionisme et utopie n'a qu'une valeur heuristique limitée pour comprendre comment ils conçoivent le développement de la Palestine au moyen du peuplement juif et de l'application, sous une forme modernisée, de principes bibliques pour réglementer la propriété. La définition de l'espace à prendre en considération pour cela les amène à débattre des limites et de l'extension de la Palestine en tant que destination d'une migration juive. (Partie I : « Concepts »)

4 Autour de 1900, les succès récents de l'Allemagne en matière d'économie et de colonisation font espérer aux sionistes que le respect d'une méthode fondée sur l'expertise et l'expérimentation permettra d'enjamber le fossé séparant leurs premières tentatives de leurs objectifs ambitieux. Outre la colonisation, intérieure et extérieure, de l'Allemagne, les Nouveaux Mondes fournissent d'autres modèles d'action. Le souci de la méthode efficace fonde aussi la réflexion sur l'organisation sociale et le système coopératif, dans laquelle Franz Oppenheimer joue un rôle essentiel. (Partie II : "Méthodologies »)

Convaincus comme nombre de leurs contemporains de vivre une révolution des transports, les sionistes allemands voient dans le chemin de fer l'instrument qui ramènera la prospérité en Palestine et la restaurera dans son statut «naturel » de lieu central. La colonie en tant qu'habitat planifié peut elle aussi être envisagée comme moyen de s'approprier utilement l'espace. La question du financement, transversale à toutes les échelles, vient clore l'analyse. (Partie III : « Instruments »)

6 Examiner le sionisme à travers son ancrage dans l'espace-temps intellectuel de l'Allemagne wilhelmienne permet d'exposer son souci de produire, de collecter et de diffuser des savoirs de type colonial dans les divers domaines de la connaissance, afin d'équiper mentalement les colonisateurs juifs de la Palestine. Leur démarche s'inscrit bien dans le processus de «transformation du monde » qui selon Jürgen Osterhammel caractérise le $\mathrm{XIX}^{\mathrm{e}}$ siècle. Le paradigme de la colonisation n'épuise cependant pas la singularité des programmes conçus par les sionistes allemands. Obsédés par leur place sur la scène internationale, compensant par l'investissement dans l'expertise une relative incapacité à y agir en tant que puissance, et se comparant sans cesse aux modèles étrangers, ils ont eu un comportement analogue à celui des élites allemandes contemporaines. 


\section{AUTEUR}

\section{OLIVIER BAISEZ}

Thèse de doctorat sous la direction de Daniel Azuelos et Horst Möller, Université de Picardie Jules Verne (Amiens) et Université Ludwig-Maximilian (Munich), soutenue le 20 novembre 2012 à Amiens. 